\title{
The Efficiency of the Banking Network in Relation to Changes in the Asset Market
}

\author{
Submitted 20/05/21, 1st revision 11/06/21, 2nd revision 28/07/21, accepted 10/08/21
}

\author{
Neda Assadollahzadehjafari ${ }^{1}$, Bahar Hafezi ${ }^{2}$, Seyed Mohsen Khalifehsoltani ${ }^{3}$
}

\begin{abstract}
:
Purpose: The purpose of writing this study is to evaluate the efficiency of the country`s banking network about the number of changes in the asset market, including the stock market and the foreign exchange market.

Design/Methodology/Approach: This paper uses the Markov rotation model for the period 2008:3-2018:3 quarterly. The Hodrick Prescott filter was used to extract exchange rate fluctuations, stock market indicators, and commercial cycles.

Findings: The results indicated that commercial cycles have a negative and significant effect on all banking network efficiency regimes. Exchange rate fluctuations had a negative and significant effect on the high regime of banking network efficiency and a positive and significant effect on the low regime of banking network efficiency. Fluctuations in the stock index had no significant effect on the high regime of efficiency, but they had a positive and significant effect on the banking network efficiency in its low regime. The results showed that the probability of a banking network being in a low-efficiency regime is increasing in the coming years.

Practical Implications: These findings provide a better understanding of how business cycles affect banking network performance regimes.

Originality/Value: The results of this study remind the Exchange and Stock Markets Organization in the country that their management should be carried out based on the level and efficiency regime of the banking network.
\end{abstract}

Keywords: Banking network efficiency, Islamic contracts, Markov rotation model.

JEL classification: C33, G32, F31.

Paper Type: Research Paper.

\footnotetext{
${ }^{1}$ Ph.D., Student in Economics, Department of Economics, Khomeinishahr Branch, Islamic Azad University, Khomeinishahr, Isfahan, Iran, Neda.asadollahzadeh@iaukhsh.ac.ir; ${ }^{2}$ Assistant Professor, Department of Economics, Khomeinishahr Branch, Islamic Azad University, Khomeinishahr, Isfahan,Iran, hafezi@iaukhsh.ac.ir;

${ }^{3}$ Assistant Professor, Department of Economics, Khomeinishahr Branch, Islamic Azad University, Khomeinishahr, Isfahan, Iran, Khalifehsoltani@iaukhsh.ac.ir;
} 


\section{Introduction}

The predominant share of financing the economy comes from the money market due to the bank-oriented nature of the country's financial system. Meanwhile, banks play a crucial role in equipping and distributing resources in various sectors of the economy, primarily supporting the manufacturing sector. The problem of the banking system crisis in the country is relatively intense, and there are serious concerns to escape this deadlock. In recent years, the share of Islamic banks' assets in the total assets of the banking network has grown significantly. The ratio had risen from $1.5 \%$ in the last 30 years to about $5 \%$ in 2018. One of the most important reasons is the increase in oil revenues and the increase in the desire of Muslims to expand Islamic laws to all economic activities (Bitar et al., 2019). During the financial crisis of 2008 and 2009, Islamic financial institutions were less affected. This issue may be due to the applicable rules of Sharia regarding risk distribution and avoidance of leveraged and speculative financial activities (Mensi et al., 2019).

Generally, banks have distanced themselves from the principles of optimal resource allocation due to repressions and financial domination of the government and imposed plans, which has led to a change in the efficiency of the country's banking network. Efficiency is a multidimensional concept that includes criteria such as the ability to receive a deposit and the amount of granted loans and non-performing loans (Partovi and Matousek, 2019). A significant percentage of the banking network granted loans have been converted into non-performing receivables (past due and doubtful receivables), which hampered the balance between acquiring deposits and re-granting loans has become problematic. The amount of granted loans in the country's banking network was varied according to different Islamic contracts.

What is essential in Islamic banking is to consider the volume of loans granted separately by contracts. In Islamic banking, the output of the banking network in estimating the efficiency of the banking network should be considered subject to the loans granted separately by Islamic contracts. The considered contracts in the present research Contracts considered in the present study are exchange contracts, partnership, and Qard al-Hasan (benevolent loans). Partnership contracts are the sum of the granted loans in Mudaraba, legal partnership, civil partnership, direct investment, and forward. Exchange contracts include installment sales, a lease on condition of ownership, and Joaleh. The bank provides all or part of the capital required for economic activity in these contracts. The difference is that the bank's profit is determined after concluding the contract and carrying out economic activity. The legal relationship of general advocacy in equipping banking resources and other financial and credit institutions can lead to more financial stability. This can be considered one of the approaches to reduce the fluctuations of commercial cycles and consequently more stability of the real sector of the economy in the context of creating a partnership structure between the supply and demand of loans to create the net wealth. 
Due to the nature of the banking network, the ability to grant loans and finance is tied to the ability to provide granting loans in the form of various contracts from the private and public sectors. If different sectors of the economy get into trouble to repay the granted loans, the banking network will also distance itself from its central role in the economy, which is to finance productive economic activities.

Evaluating the effect of the bank-oriented financing in the country and the determining role of exchange rate fluctuations in the cost of goods and services and household consumption costs, as well as the complementary role that the capital market can play in financing the performance and efficiency of the banking network, is very important. The present study is organized into five sections. Section two provides the theoretical foundations and research background. Section three discusses the methodology related to the research models: section four and five present the research findings and conclusion, respectively.

\section{Literature Review}

Exchange fluctuations can cause problems for the public and private sectors by changing the cost of products on the one hand and creating uncertainty about decisionmaking on the other hand. The ability to grant loans by banking networks in various Islamic contracts is tied to the degree of success in collecting claims from the public and private sectors. It can be said that non-performing receivables are the result of two parts. The first part is the voluntary nature of the borrower, and the second part is influenced by factors outside the borrowers' control, which can be attributed to macroeconomic and financial conditions such as oil prices, exchange rates, and fluctuations. Therefore, it is necessary to consider and manage the factors that affect non-performing loans and receivables and consequently the efficiency of banks in inter and extra-organizational (Heidari et al., 2010). Perico et al. (2016) carried out a study entitled "Estimating the Performance of Brazilian Banks: An Envelopment Analysis of Bootstrap Data," using DEA Bootstrap to investigate the performance of Brazilian banks in 2010-2013. The results showed that large Brazilian banks performed moderately during this period. Khajeh Hassani et al. (2016), in a study entitled "Evaluating the efficiency of the Iranian banking system using the Bootstrap coverage analysis approach and the SW algorithm," evaluated the efficiency of 25 public and private banks in 2011 using the bootstrap data envelopment analysis approach. The results showed that banks with a higher share of assets are relatively more efficient in scale and management. Private Banks have been more efficient than state-owned banks.

Amiri (2018) measured the efficiency of 15 selected Iranian banks, including private, state-owned, and private and state-owned banks, in 2006-2015 using the data envelopment analysis method. In the next stage, the effect of intra-bank variables (investment to total assets ratio, debt to total assets, and bank size) and macroeconomic (economic growth, inflation rate, exchange rate change, inflation rate fluctuations, exchange rate fluctuations, and liquidity growth rate) on efficiency was 
evaluated using the panel models. According to the research results, the uncertainty of exchange rate fluctuations and inflation has a negative effect on the efficiency of Iranian banks. Moreover, the inflation and exchange rate changes had a negative and significant relationship with the efficiency of Iranian banks. Ismaili (2018) investigated the role of commercial cycles in the overdue receivables of the country's banks using intermediate filters. In this research, the commercial cycles in the Iranian economy have been extracted using the intermediate filter model. Then, the most critical factors affecting the unique contents of the banking system have been identified using the heuristic factor analysis method. Finally, the effect of the occurrence of business cycles on changes in overdue bank receivables was examined. The results showed that the overdue receivables of banks had a cyclical behavior, which decreased during the prosperity and increased during the recession.

Partovi and Matousek (2019), in a study entitled "Banking efficiency and nonperforming receivables: evidence from Turkey," calculated Turkish banking efficiency from December 2003 to December 2017 under the constant return to scale hypothesis using a data envelopment analysis model focusing on non-performing receivables as an undesirable output. The results of the multiple regression model in this study showed that non-performing receivables had a negative impact on banking efficiency in this country, which somehow confirms the hypothesis of bad management in the banking sector. The study showed that non-performing receivables have a negative effect on the efficiency and stability of the bank because they degrade the quality of the bank's assets.

In the current literature, non-performing receivables are considered as a controlled variable or a lousy output. All studies showed that NPLs (non-current receivables) contribute to the inefficiency of banks. Some studies revealed that the main problem with papers that examine the effects of NPLs is that they assume NPLs as a controlled variable, not as an undesirable output that directly affects the production process. Therefore, NPL is considered an undesirable output.

Shamshur and Weill (2019) examined the relationship between banking efficiency and credit costs of borrowing companies in 9 European countries. The research hypothesis states that banking efficiency is associated with lower lending rates and consequently lower credit costs. The effect of bank efficiency on credit costs varies depending on the size of the company and the size of the bank. The results show that less banking competition facilitates higher efficiency transfers to reduce credit costs. Factors that increase banking efficiency increase access to credit.

\section{Research Methodology}

This research has investigated the effect of exchange rate and stock fluctuations along with commercial cycles on the efficiency of the banking network based on the granted loans by Islamic contracts in 2008:3-2018:3. The data relating to the exchange rate, GDP at the constant price in 2011, and stock price index were collected from the 
database of the Ministry of Economy and Finance and the data related to efficiency calculation inputs (volume of bank deposits, prudent behavior of banks, return on equity, and size of the banking network) has been extracted from the country's banking network balance sheet and Bourseview.com. Moreover, the data related to the performance calculation outputs (loans granted in exchange contracts, partnership contracts, Qard al-Hasan (benevolent loans), overdue receivables) have been extracted from the Central Bank. The prudential behavior of the banking network towards the granted loans to the banks' assets shows the risky behavior and the degree of the prudence of the banking network in paying the loans. The size of the banking network is the total assets of the entire banking network of the country, and the return on equity is obtained by dividing the total net profit of the banking network by the total equity and shows the bank's ability to generate net profit from shareholders. The following model has been used based on the studies of Shamshur and Weill (2019) and Maetusek and Partovi (2019):

$$
\text { eff } f_{t}=c\left(s_{t}\right)+\operatorname{cycle}\left(s_{t}\right)+\operatorname{vexc}\left(s_{t}\right)+\operatorname{vstock}\left(s_{t}\right)+\varepsilon\left(s_{t}\right)
$$

The terms in Equation (1) are as follows:

ef $f_{t}$ : Banking network efficiency, cycle $\left(s_{t}\right)$ : Commercial cycles in different regimes of banking network efficiency, vex $\left(s_{t}\right)$ : Exchange rate fluctuations in different regimes of banking network efficiency, $\operatorname{vstock}\left(s_{t}\right)$ : Stock index fluctuations in different regimes of banking network efficiency, $c\left(s_{t}\right)$ : Intercept depends on the regime, $\varepsilon\left(s_{t}\right)$ : Error Term depends on the regime.

Three econometric methods have been used to extract the experimental results of the research. In the first step, the EGARCH approach has been used to extract exchange rate fluctuations and stock indicators. The Hodrick-Prescott filter has been used to extract business cycles. In the second step, the Bootstrap Data Envelopment Analysis Model and Simar and Wilson's (1998) algorithm have been used to investigate the efficiency of the banking network. Markov rotation approach has been used to investigate the effect of exchange rate and stock fluctuations along with commercial cycles in the context of regime change. In the following, the models used are examined separately.

\subsection{Heterogeneous Conditional Variance Model}

Financial time series often exhibit the cluster turbulence phenomenon, which means that fluctuations that occur in one period are transmitted to subsequent periods, but over time their intensity decreases. Since such data reflects trade between buyers and sellers, various news sources and other external economic events can affect the time series model. News can lead to different interpretations, and the occurrence of a particular economic event, such as an oil crisis at the same time, can aggravate the situation (different interpretations) (Philip, 1988). Methods that can measure the turbulence of a series are autoregressive conditional variance heterogeneity $(\mathrm{ARCH})$ 
models. These models make it possible to take advantage of the standard deviation of the sample, formulate the conditional variance of the time series from the maximum likelihood method, and provide a systematic framework for turbulence modeling. The variance of the conditional error prediction obtained from these models shows the amount of turbulence, which changes over time. In most studies, it is used as a measure of fluctuations and uncertainty.

The ARCH model was proposed by Engle (1982). This model assumes that the random sentence has a mean of zero and is serially uncorrelated, but its variance is assumed variable, provided it has its past information. In this case, the variance is expected not to be constant during the stochastic random process and to function the error sentence behavior. The ARCH model can explain the conditional variance trend based on its past information. This method ignores rational expectations, which cannot identify the effect of predicting fluctuations of past periods on currency fluctuations. The GARCH model, which is an extension of the ARCH model, was first introduced by Bollerslev (1986) to solve the ARCH method problem. The GARCH model also limits the effect of ARCH by reducing the number of parameters geometrically. This means that the effect of a shock on current fluctuations decreases over time (Verbeek, 2005).

The Model structure GARCH (p, q) can be written as follows.:

$$
\begin{aligned}
& \left(\mathrm{y}_{\mathrm{t}} \mid £_{t-1}\right)=a_{0}+\sum_{i=1}^{\mathrm{S}} a_{i} y_{\mathrm{t}-\mathrm{i}}+\gamma X_{t}+\varepsilon_{t} \\
& \left(\varepsilon_{\mathrm{t}} \mid £_{\mathrm{t}-1}\right) \sim \mathrm{N}\left(0, \delta_{\mathrm{t}}^{\mathrm{r}}\right) \\
& \delta_{\mathrm{t}}^{\mathrm{r}} \equiv \mathrm{E}\left(\varepsilon_{\mathrm{t}}^{2} \mid £_{t-1}\right) \equiv \mathrm{h}_{\mathrm{t}}=\beta_{0}+\sum_{\mathrm{i}=1}^{\mathrm{q}} \beta_{\mathrm{i}} \varepsilon_{\mathrm{t}-\mathrm{i}}^{2}+\sum_{\mathrm{j}=1}^{\mathrm{p}} \theta_{\mathrm{i}} \mathrm{h}_{\mathrm{t}-\mathrm{j}}+\mathrm{v}_{\mathrm{t}} \\
& \beta_{0} \geq 0, \beta_{\mathrm{i}} \geq 0, \theta_{\mathrm{j}}>0 ; \sum_{\mathrm{i}=1}^{\mathrm{q}} \beta_{\mathrm{i}}+\sum_{\mathrm{j}=1}^{\mathrm{p}} \theta_{\mathrm{j}}<1 ; \mathrm{v}_{\mathrm{t}} \sim \operatorname{IIN}\left(0, \delta_{\mathrm{v}}^{2}\right)
\end{aligned}
$$

$\mathrm{y}_{\mathrm{t}}$ is the dependent variable at $\mathrm{t}$ period, $X_{t}$ is the explanatory variable in period $\mathrm{t}, \varepsilon_{\mathrm{t}}$ is the amount of residue in period $t$, which indicates the existence of shocks and new information that the economic factor was previously unaware of. If $\varepsilon_{\mathrm{t}}>0$, then the shock is positive and if $\varepsilon_{\mathrm{t}}<0$, then the shock is negative. $\delta_{\mathrm{t}}^{r}$ or $\mathrm{h}_{\mathrm{t}}$ is the conditional variance, which is interpreted as predicting time series fluctuations in period t. $£_{t-1}$ includes a set of information until t-1 plus $\varepsilon_{\mathrm{t}-\mathrm{i}}^{2}$. Equation (2), which is a criterion to determine the conditional mean, is a function of exogenous variables with an error term $\varepsilon_{\mathrm{t}}$. In this equation, if noise $\left(\varepsilon_{\mathrm{t}}\right)$ has a normal distribution with zero mean and conditional variance $h_{t}$, Equation (3) can be proposed.

Equation (3) determines the conditional variance. The conditional variance equation consists of three parts of mean fluctuations $\left(\beta_{0}\right)$, ARCH term $\left(\varepsilon_{t-i}^{2}\right)$ and GARCH term $\left(\mathrm{h}_{\mathrm{t}-\mathrm{j}}\right)$. The ARCH term is the news index of the previous period, which is obtained from the second power of the conditional mean equation residue and appears as a delay variable in the conditional variance equation. The GARCH term represents the prediction of fluctuations in previous periods. In Equation (3), the conditional variance 
residue has a normal distribution with variance $\delta_{\mathrm{v}}^{2}$. In other words, the noise here will be white noise. This condition is true in all conditional heterogeneity variance models. An important limitation of the ARCH and GARCH methods is their symmetry. That is, they consider the absolute value of changes in predicting fluctuations and ignore their sign. Therefore, the effects of negative shock and positive shock of the same magnitude on the series fluctuations are considered the same. While series fluctuations do not show the same reaction to the type of news (negative and positive shocks). Thus, it is necessary to use an asymmetric model Thus, to solve this problem and to analyze the behavior of fluctuations (Verbeek, 2005). One of the models used in asymmetric fluctuations is the EGARCH model proposed by Nelson (1991). This model logarithmically calculates the conditional variance. The logarithmic calculation of conditional variances eliminates the need for using the square of error sentences and thus, the model goes out of symmetry. The conditional variance equation of the EGARCH model is calculated as Equation (4):

$\operatorname{EGARCH}(\mathrm{p}, \mathrm{q}): \log \left(\sigma_{\mathrm{t}}^{r}\right)=\beta_{0}+\sum_{\mathrm{i}=1}^{\mathrm{q}} \beta_{\mathrm{i}} \log \left(\sigma_{\mathrm{t}-\mathrm{i}}^{r}\right)+\sum_{\mathrm{k}=1}^{\mathrm{r}} \theta_{\mathrm{k}} \frac{\varepsilon_{\mathrm{t}-\mathrm{k}}}{\sigma_{\mathrm{t}-\mathrm{k}}}+$ $\sum_{\mathrm{j}=1}^{\mathrm{p}} \varphi_{\mathrm{j}}\left|\frac{\varepsilon_{\mathrm{t}-\mathrm{j}}}{\sigma_{\mathrm{t}-\mathrm{j}}}\right|+\mathrm{v}_{\mathrm{t}}$

In which, $\theta \cdot \beta$, and $\varphi$ are constant parameters. If $\theta<0$ In this case, positive shocks spread fewer fluctuations than negative shocks. If $=0$, the exponential model is asymmetric. The EGARCH model is superior to other asymmetric models such as the Threshold Arch (TGARGH) in the following cases:

1. Logarithmic transformation assumes positive conditional variance.

2. Estimations from the exponential model will not be sensitive to the presence of outliers.

3. This model has no restrictions on the parameters and is sufficient for the EGARCH process durability. $\varepsilon_{\mathrm{t}}$ in Equation (1) has a normal distribution and $\left|\sum_{\mathrm{i}=1}^{\mathrm{q}} \beta_{\mathrm{i}}\right|$ in equation (3) is less than one.

In this study, EGARCH model has been used to extract exchange rate fluctuations and stock index.

\subsection{Bootstrap Envelopment Analysis Model}

Bootstrap data envelopment analysis approach based on Simar and Wilson (1998) algorithm with input-driven approach with variable-to-scale returns has been used to estimate efficiency.

The first DEA estimator was introduced by Farrell to measure technical efficiency, which became popular when the DEA was introduced to estimate efficiency rankings and consider returns on a constant scale (CCR model). Then, a DEA estimator that makes it possible to consider variable scale returns (VRS) was introduced (BCC model). In this study, the VRS characteristic is used according to Hollingsworth \& 
Smith. They pointed out that the model assuming VRS must be used when using ratios in DEA; otherwise, incorrect results may be obtained. In addition, the input formula of the DEA axis is used because in these conditions, the output values are maximized by keeping the input values constant. Therefore, the input-axis efficiency rating estimator, assuming VRS can be obtained by solving the linear program described below for the unit under evaluation:

Min $\theta$

$\sum_{j=1}^{n} \lambda_{j} y_{r j} \geq y_{r 0} \quad r=1,2, \ldots, S_{1}$

Subject to $\sum_{j=1}^{n} \lambda_{j} x_{i j} \leq \theta x_{i 0} \quad i=1,2, \ldots, m_{i}$

$\sum_{j=1}^{n} \lambda_{j}=1 \quad j=1,2, \ldots, n_{i}$

$\lambda_{j} \geq 0 \quad j=1,2, \ldots, n_{0}$

In which, $\theta$ is the efficiency rating of the evaluated unit (zero unit), $x_{i j}, y_{r j}, \lambda_{j}$ respectively are the ith input, rth output, and jth unit shadow price, which are calculated from the above equation.

Researchers have introduced the nature of bootstrap techniques as an alternative method of conducting inference, where the sample size is not large or the sampling distributions because of nonlinearity or pre-test etc. are not analytically known. Errors in estimating efficiency rankings can be avoided by using bootstrap techniques. Eight steps are observed following Bogetoft, Otto, and Walden to implement the Bootstrap algorithm to obtain a sample of Bootstrap estimates from the initial DEA rankings (indicated here by the symbol).

1. $\hat{\theta}^{k}$ is calculated as a solution for DEA model for $k=1,2, \ldots \ldots, n_{0}$.

2. $\hat{\theta}^{1}, \ldots, \hat{\theta}^{n}$ is used through smooth sampling to get a bootstrap iteration $\hat{\theta}^{1 *}, \ldots, \hat{\theta}^{n *}$ from bootstrap. The steps to implement this are:

A) Sampling is implemented by placing from $\hat{\theta}^{1}, \ldots ., \hat{\theta}^{n}$ and the results are $\beta^{1}, \ldots, \beta^{n}$.

B) Standard normal discrete random variables $\varepsilon^{1}, \ldots, \varepsilon^{n}$ are simulated.

C) $\hat{\theta}^{k}$ is calculated by smoothing of sampled values (Step A):

$\hat{\theta}^{k}=\left\{\begin{array}{c}\beta^{k}+h \varepsilon^{k} \\ 2-\beta^{k}-h \varepsilon^{k}\end{array}\right.$ if $\beta^{k}+h \varepsilon^{k} \leq 1$

$h$ is the bandwidth parameter, and it is calculated using the "finger rule". It should be noted that in the end $\hat{\theta}^{k} \leq 1$. 
D) $\hat{\theta}^{k *}$ is calculated through $\hat{\theta}^{k *}=\bar{\beta}+\frac{1}{1+\frac{h^{2}}{\hat{\sigma}^{2}}}\left(\tilde{\theta}^{k}-\bar{\beta}\right)$, while $\hat{\sigma}^{2}=$ $\frac{1}{n} \frac{1}{n} \sum_{k=1}^{n}\left(\tilde{\theta}^{k}-\overline{\hat{\theta}}\right)$ and $\bar{\beta}=\frac{1}{n} \sum_{k=1}^{n} \beta^{k}$

E) Bootstrap input is calculated through $x^{k b}=\frac{\widehat{\theta}^{k}}{\widehat{\theta}^{k *}} x^{k}$.

F) The initial DEA program is re-solved for each of the prototype observations using a reference set constructed by Bootstrap inputs in step (c) to estimate its values.

G) $\hat{\theta}^{b}=\hat{\theta}^{n b}$ for $b=1, \ldots, B$ from step $A$ is repeated to obtain Bootstrap value.

$\mathrm{H})$ The mean and variance of the bootstrap values $\hat{\theta}^{b}, \ldots, \hat{\theta}^{n b}$ are calculated obliquely to obtain the corrected estimate in terms of $\tilde{\theta}^{k *}$ bias.

$\hat{\theta}^{k}$ is calculated to estimate the bootstrap bias for the initial DEA estimator:

$\operatorname{bias}^{k *}=\frac{1}{B} \sum_{b=1}^{B} \hat{\theta}^{k b}-\hat{\theta}^{k}=\bar{\theta}^{k *}-\hat{\theta}^{k}$

In which, $\hat{\theta}^{k b}$ is the bootstrap value and B the number of bootstrap repetitions. Therefore, the bias-corrected estimator can be calculated as follows:

$\tilde{\theta}^{k *}=\hat{\theta}^{k}-$ bias $^{k *}=\hat{\theta}^{k}-\bar{\theta}^{k *}+\widehat{\theta}^{k}=2 \hat{\theta}^{k}-\bar{\theta}^{k *}$

This bias correction can cause some additional disruption and it will be necessary to calculate the variance of the sample bootstrap values $\hat{\theta}^{k b}$ :

$\hat{\sigma}^{k}=\sqrt{\left(\frac{1}{B} \sum_{b=1}^{B} \widehat{\theta}^{k b}-\widehat{\theta}^{k *}\right)^{2}}$

Finally, a simple rule is that if the absolute value of the bias is greater than the standard deviation of the bootstrap values (Equation below), the corrected estimates should be preferred to the initial values (Anvari Rostami et al., 2016).

bias $^{k *}>\widehat{\sigma}^{k}$

\subsection{Markov Switching Model}

In nonlinear models, it is assumed that the behavior of the variable on which the modeling is performed is different and changes in different situations. Nonlinear models are divided into two main groups regarding the speed of change from one state to another. Switching from one regime to another is done slowly in some of these nonlinear models. In contrast to these models, regime conversion is considered exogenous in Markov's transfer model proposed by Hamilton (Enders, 2004). One of the advantages of the Markov-switching method compared to other methods is separating the internalization of the observations of one variable and the separation of the internalization of the relationships between the observations of the variables. 
For this reason, the Markov-switching method is entirely different from models based on the structural failure and virtual variables. In structural failure-based models, the years of structural failure are determined exogenously or endogenously regardless of the probabilities. In the Markov-switching model, probabilities are used to separate time series variables or relationships between variables into two or more regimes. Then, the probability of transition from one regime to another or the probability of remaining in the current regime is calculated.

However, in the case of structural failure, such issues are irrelevant, and the possibility of predicting the transition from one situation to another is unknown. In models based on the structural failure, it is impossible to predict changes in variables, but it is possible to predict changes in variables from one regime to another in the Markov switching model. Markov switching model can be divided into different types according to which part of the autoregression model is dependent on the regime and is transferred under its effect. The models that are most considered in economic studies can be classified into four different modes, including Markov Switching in mean (MSM), intercept (MSI), autoregressive parameters (MSA), and heteroscedasticity $(\mathrm{MSH})$ in error time variance. In some cases, a combination of the above is used. A summary of the different modes of the Markov rotation model is presented in Table (1):

Table 1. Types of Markov Rotation Models

\begin{tabular}{|c|c|c|c|}
\hline $\begin{array}{c}\text { Term dependent on } \\
\text { regime }\end{array}$ & $\begin{array}{c}\text { Error sentence } \\
\text { distribution }\end{array}$ & Equation & Model name \\
\hline Mean & $\varepsilon_{t} \sim I I D\left(0, \sigma^{2}\right)$ & $\begin{aligned} \Delta y_{t}-\mu\left(s_{t}\right)=\sum_{i=1}^{p} & \alpha_{i}\left(\Delta y_{t-i}\right. \\
& -\mu\left(s_{t-i}\right) \\
& -\varepsilon_{i}\end{aligned}$ & $\begin{array}{l}\operatorname{MSM}(\mathrm{m})- \\
\mathrm{AR}(\mathrm{p})\end{array}$ \\
\hline Intercept & $\varepsilon_{t} \sim I I D\left(0, \sigma^{2}\right)$ & $\begin{array}{c}\Delta y_{t}=c\left(s_{t}\right)+\sum_{i=1}^{p} \alpha_{i}\left(\Delta y_{t-i}\right) \\
+\varepsilon_{i}\end{array}$ & $\begin{array}{l}\operatorname{MSI}(\mathrm{m})- \\
\operatorname{AR}(\mathrm{p})\end{array}$ \\
\hline $\begin{array}{l}\text { Error sentence } \\
\text { variance }\end{array}$ & $\varepsilon_{t} \sim I I D\left(0, \sigma^{2}\left(s_{t}\right)\right.$ & $\Delta y_{t}=c+\sum_{i=1}^{p} \alpha_{i}\left(\Delta y_{t-i}\right)+\varepsilon_{i}$ & $\begin{array}{l}\mathrm{MSH}(\mathrm{m})- \\
\mathrm{AR}(\mathrm{p})\end{array}$ \\
\hline $\begin{array}{l}\text { Coefficient of co- } \\
\text { explanation sentence }\end{array}$ & $\varepsilon_{t} \sim I I D\left(0, \sigma^{2}\right)$ & $\begin{array}{c}\Delta y_{t}=c+\sum_{i=1}^{p} \alpha_{i}\left(s_{t}\right)\left(\Delta y_{t-i}\right) \\
+\varepsilon_{i}\end{array}$ & $\begin{array}{l}\operatorname{MSA}(\mathrm{m})- \\
\operatorname{AR}(\mathrm{p})\end{array}$ \\
\hline
\end{tabular}

Source: Kazerouni et al. (2012).

\section{Research Findings}

The commercial cycle, exchange rate fluctuations, and stocks variables should be initially extracted before analyzing the Markov rotation model. The Hodrick-Prescott filter is used to extract business cycles, as shown in Figure (1). 
The effect of symmetric negative and positive shocks is considered in the GARCH model. According to experimental studies, stock and exchange rate fluctuations do not react equally to negative and positive shocks. Therefore, it is necessary to use an asymmetric model to analyze the behavior of fluctuations. Accordingly, the asymmetric EGARGH model is used to extract exchange rate and stock fluctuations in this study.

Figure 1. Extraction of Commercial Cycles

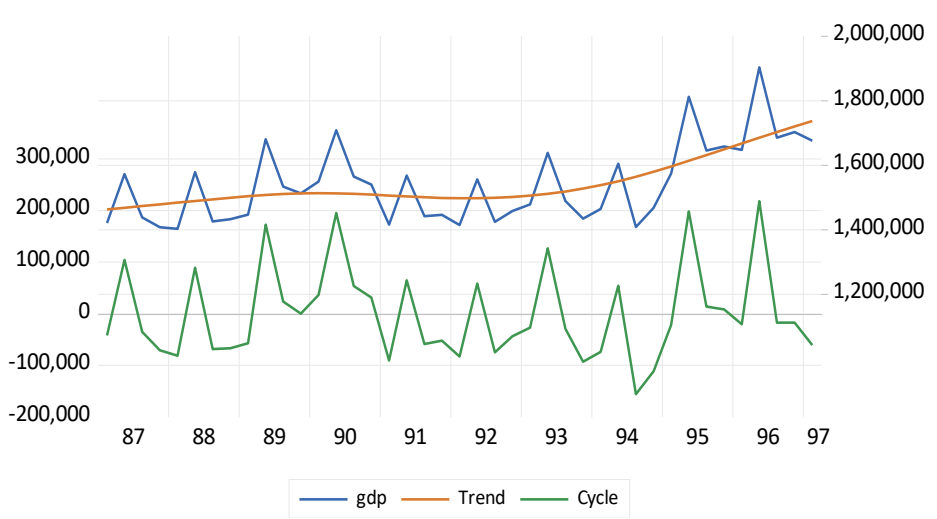

Source: Research Findings.

It is first necessary to estimate the conditional mean equation to estimate the EGARCH model. The correlogram of stock series and exchange rate and Akaike Information Criterion (AIC) \& Schwarz Baysesian Criterion (SBC) estimation equations were the basis for selecting the optimal interval of models. The EGARCH model $(1,1)$ has been selected as the most appropriate model in terms of the BoxJenkins criterion among the estimated equations based on the correlogram of the residual squares of the conditional mean equations of the stock and the exchange rate. The relevant results are presented in Table (2).

Table 2. EGARCH model estimation results $(1,1)$

\begin{tabular}{|c|c|c|c|c|c|c|c|c|c|}
\hline $\begin{array}{c}\text { Dependent } \\
\text { variable }\end{array}$ & \multicolumn{4}{|c|}{ Stock } & $\begin{array}{c}\text { Dependent } \\
\text { variable }\end{array}$ & \multicolumn{4}{|c|}{ LEXC } \\
\hline \multicolumn{5}{|c|}{ conditional mean equation } & \multicolumn{5}{|c|}{ conditional mean equation } \\
\hline Variable & $\begin{array}{l}\text { Coeffi } \\
\text { cient }\end{array}$ & $\begin{array}{l}\text { Standard } \\
\text { deviation }\end{array}$ & $\begin{array}{c}\text { Z } \\
\text { statisti } \\
\text { cs }\end{array}$ & $\begin{array}{c}\text { probabilit } \\
\text { y level }\end{array}$ & Variable & $\begin{array}{c}\text { Coeffi } \\
\text { cient }\end{array}$ & $\begin{array}{l}\text { Standard } \\
\text { deviation }\end{array}$ & $\begin{array}{c}\mathrm{Z} \\
\text { statisti } \\
\text { cs }\end{array}$ & $\begin{array}{c}\text { probabilit } \\
\text { y level }\end{array}$ \\
\hline Intercept & 60.423 & 3.479 & \begin{tabular}{|c|}
1.366 \\
7 \\
\end{tabular} & 0.000 & Intercept & 8.725 & 1.E7-101 & \begin{tabular}{|c}
$\mathrm{E}+101$ \\
5.1 \\
\end{tabular} & 0.000 \\
\hline \multirow[t]{2}{*}{ Stock $_{t-1}$} & 0.813 & 0.1940 & 4.191 & 0.000 & $\operatorname{trexch}_{\mathrm{t}-1}$ & 0.874 & 0.00033 & $\begin{array}{c}25.77 \\
99\end{array}$ & 0.000 \\
\hline & & & & & $\operatorname{trend}_{\mathrm{t}}$ & 0.051 & 0.0000121 & $\begin{array}{c}42.49 \\
44\end{array}$ & 0.000 \\
\hline
\end{tabular}


The Efficiency of the Banking Network in Relation to Changes in the Asset Market 110

\begin{tabular}{|c|c|c|c|c|c|c|c|c|c|}
\hline \multicolumn{5}{|c|}{ Conditional variance equation } & \multicolumn{5}{c|}{ Conditional variance equation } \\
\hline Intercept & 18.966 & $2 . \mathrm{E} 4-101$ & $\begin{array}{c}\mathrm{E}+101 \\
7.8\end{array}$ & 0.000 & Intercept & -5.135 & 0.295 & -17.39 & 0.000 \\
\hline$\left|\frac{\varepsilon_{\mathrm{t}-\mathrm{j}}}{\sigma_{\mathrm{t}-\mathrm{j}}}\right|$ & 1.489 & 0.369 & 4.03 & 0.000 & $\left|\frac{\varepsilon_{\mathrm{t}-\mathrm{j}}}{\sigma_{\mathrm{t}-\mathrm{j}}}\right|$ & 1.956 & 0.568 & 3.439 & 0.000 \\
\hline$\frac{\varepsilon_{\mathrm{t}-\mathrm{k}}}{\sigma_{\mathrm{t}-\mathrm{k}}}$ & 1.749 & 0.227 & 7.703 & 0.000 & $\frac{\varepsilon_{\mathrm{t}-\mathrm{k}}}{\sigma_{\mathrm{t}-\mathrm{k}}}$ & 3.31 & 0.498 & 6.645 & 0.000 \\
\hline $\log \left(\sigma_{t-i}^{2}\right)$ & -0.037 & 0.018 & -2.044 & 0.0409 & $\log \left(\sigma_{t-i}^{2}\right)$ & -0.123 & 0.067 & -1.818 & 0.069 \\
\hline
\end{tabular}

Source: Research Findings.

Based on the results of Table (2), the logarithm fluctuations of the exchange rate and stock index are obtained in the form of Figure (2).

Figure 2. Logarithm Fluctuations in Exchange Rates and Stock Index

rlexc

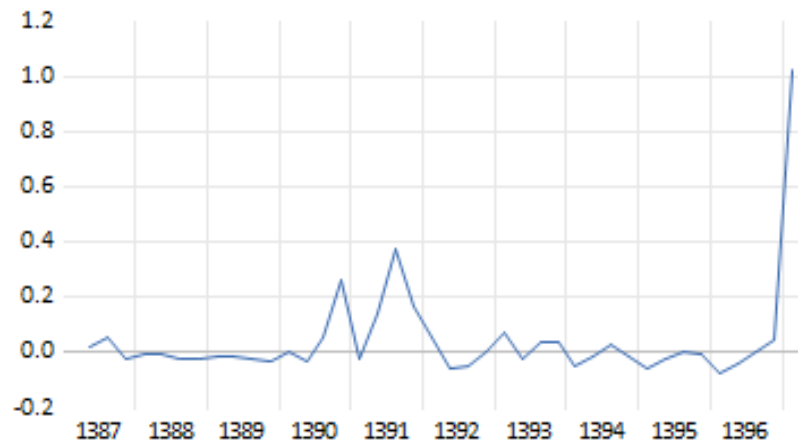

vstock

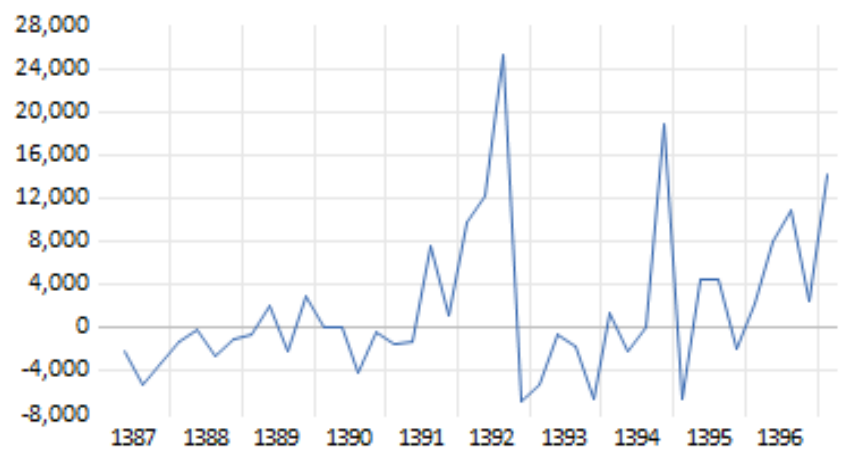

Source: Research Findings.

The input-driven approach with variable efficiency has been used based on the studies of Perico et al. (2016), Wank et al. (2016), and Matousek and Partovi (2019). The following is the banking network efficiency trend in Figure (3): 
Figure 3. Banking Network Efficiency Process

eff

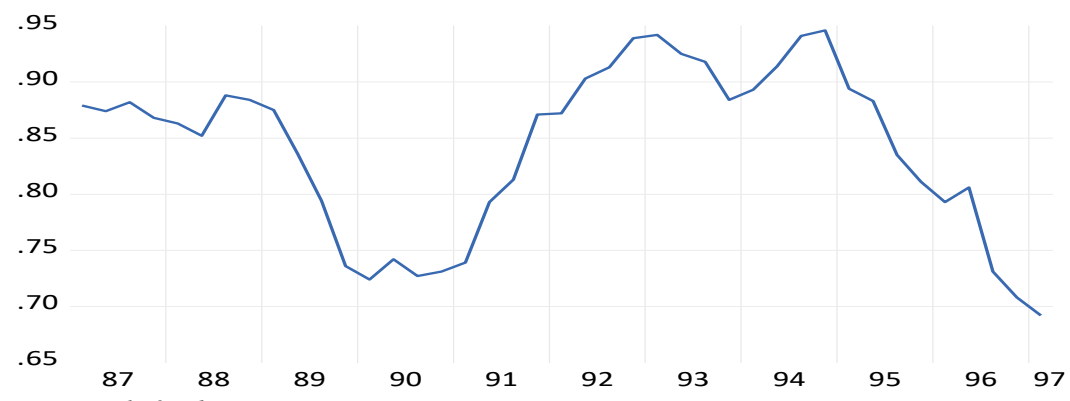

Source: Research findings.

According to Figure (3), the lowest efficiency of the banking network dates back to the first quarter of 2018, when the efficiency of the banking network has reached $69 \%$. Moreover, the efficiency of the banking network has been at a low level between 2010 and 2012. The willingness of individuals to deposit in the banking network has decreased when fluctuations and growth in the foreign exchange and stock markets have increased, and consequently, granting loans have grown less than before. On the other hand, the ability to repay the granted loans has also decreased, given the increase in costs due to the growth of the exchange rate. The cases mentioned above can be considered the reason for the decrease in the efficiency of the banking network in these periods.

One of the issues that need to be considered before estimating the model is the time series durability of the variables. The problem of false regression of time series models is also actual for Markov rotational models. Therefore, using the unit convergence root test in econometric models is essential to ensure the accuracy and validity of the results. It is necessary to perform a unit root test for each dependent variable and the residual template to ensure convergence. Given that the variables of commercial cycles, exchange rate fluctuations, and stock index have been de-trended, there is no need to perform a Durability test. In the present study, the root test of the HEGY seasonal unit for the banking network efficiency variable is presented in Table (3).

Table 3. Unit Root Test of Research Variables

\begin{tabular}{|c|c|c|c|}
\hline Variable & Hull hypothesis & $\begin{array}{c}\text { Computational } \\
\text { statistics }\end{array}$ & $\begin{array}{c}\text { Probability } \\
\text { level }\end{array}$ \\
\hline \multirow{2}{*}{ Eff } & Seasonal unit root with intercept & 34.771 & 0.000 \\
\cline { 2 - 4 } & $\begin{array}{c}\text { Seasonal unit root with intercept and } \\
\text { process }\end{array}$ & 32.768 & 0.000 \\
\hline
\end{tabular}

Source: Research Findings.

Since economic time series variables experience some structural failures over some time, usually for various reasons such as war, financial panic, significant changes in government policies, etc., or change the situation (regime), so several models 
(equations) should be used instead of a simple model so to explain the behavior of such variables. Markov switching model makes it possible to combine several models through the transfer mechanism (Pourebadollahan Covich et al., 2018). The effect of variables may be different in different regimes of banking network efficiency. This can be tested through Markov rotation models.

Markov switching models are created according to the possibility of changing the mean, intercept, and coefficients of autoregression sentences. It is necessary to have two conditions to choose the optimal model. First, the null hypothesis of the lack of regime change must be rejectable in the model. Second, the model should be more appropriate in terms of Akaike criteria among other possible models in which the first condition is met. LR test and SC and AIC information criteria determine the optimal regime in the MS model.

Using nonlinear methods such as Markov rotational model should be identified before determining the number of regimens and the number of degrees of self-regression. This is shown in Table (4).

Table 4. Nonlinearity Test

\begin{tabular}{|c|c|c|c|}
\hline Result & probability level & Statistics value & Statistics \\
\hline $\begin{array}{c}\text { The use of a nonlinear } \\
\text { model is approved }\end{array}$ & 0.000 & 45.99 & $\mathrm{Chi}^{\wedge} 2(7)$ \\
\hline
\end{tabular}

Source: Research Findings.

Based on the Akaike and Schwarz intelligence criteria, two optimal regimes have been identified. Therefore, the model is MSIH (2). The results of estimating the above model in Table (5) are as follows.

Table 5. Estimation of the Main Research Model

\begin{tabular}{|c|c|c|c|c|}
\hline Variable & Coefficient & Standard deviation & T statistic & Probability level \\
\hline $\mathrm{C}(0)$ & 0.881 & 0.0046 & 190.00 & 0.000 \\
\hline $\mathrm{C}(1)$ & 0.777 & 0.0121 & 63.8 & 0.000 \\
\hline cycle(0) & -0.347 & 0.043 & -8.02 & 0.000 \\
\hline cycle(1) & -0.831 & 0.153 & -5.4 & 0.000 \\
\hline RLEXC(0) & -0.084 & 0.0063 & -13.36 & 0.000 \\
\hline RLEXC(1) & 0.0086 & 0.0033 & 2.56 & 0.018 \\
\hline VSTOCK(0) & 0.076 & 0.058 & 1.29 & 0.214 \\
\hline VSTOCK(1) & 0.094 & 0.032 & 2.96 & 0.008 \\
\hline Sigma(0) & 0.0192 & 0.0034 & - & - \\
\hline Sigma(1) & 0.0488 & 0.0084 & - & - \\
\hline
\end{tabular}

Source: Research Findings.

According to Hamilton (1989), the intercept with a smaller coefficient indicates s the regime and the low level, and the more significant coefficient indicates the regime and the high level. In the present study, regime 0 indicates the high level and regime of efficiency of the banking network, and regime 1 indicates the low level and regime of efficiency of the banking network. As can be observed, commercial cycles in both 
regimes have a significant adverse effect on the efficiency of the banking network. This shows that changes in GDP significantly affect the efficiency of the banking network. On the other hand, the emergence of commercial cycles can affect uncertainty in decision-making and investment.

According to the results, the emergence of commercial cycles under all regimes has led to a decrease in the efficiency of the banking network. The interesting point is the different effects of exchange rate fluctuations in different regimes of banking network efficiency. When the efficiency of the banking network is at its high level, the occurrence of exchange rate fluctuations leads to a decrease in the efficiency of the banking network. Also, when the efficiency of the banking network is at a low level, exchange rate fluctuations have led to an increase in the efficiency of the banking network. It can be said that the low efficiency of the banking network usually occurs when the country is in a recession and the government get into trouble to generate revenue and cover its costs. Exchange rate fluctuations in the country are mainly due to the increase in the exchange rate and have been significantly different from the exchange rate of the approved budget during the last two years.

Figure 4. Classification of Regimes and Related Probability
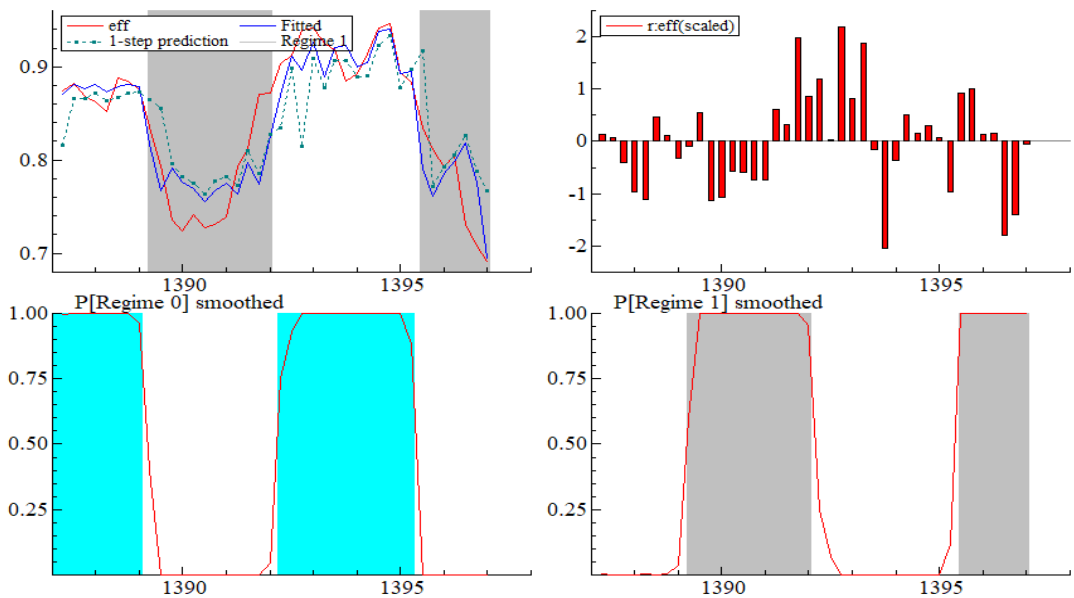

Source: Research Findings.

The government has been able to earn foreign exchange earnings from the difference and repay part of the receivables of the banking network. In this way, the network's ability to grant loans in the form of various contracts, even temporarily, increases. On the other hand, when the efficiency of the banking network is at its highest level, which usually occurs in prosperity, the occurrence of exchange rate fluctuations and its increase leads to an increase in the cost of goods and services, as well as a decrease in purchasing power and repayment capacity. This effect can overcome the effect of foreign exchange earnings in such circumstances and, in general, lead to a decrease in the efficiency of the banking network. Fluctuations in the stock index have a positive and significant effect only when the efficiency of the banking network is at a low level 
and has no significant effect when the efficiency is at a high level. This issue can be due to the small share of the country's capital market in financing businesses. If the efficiency of the banking network is low, creating attractiveness can be used in the country's capital market as a tool to improve the efficiency of the banking network.

Most of the companies listed on their stock exchanges are recipients of banking network loans. These companies will have the purchasing power and the ability to repay higher loans with the growth of the stock index. Hence, the possibility of depositing as well as repaying the loans by them increases. The classification of regimes and the probabilities associated with regimes is shown in Figure (4).

Table 6. Regime Transfer Probability Matrix

\begin{tabular}{|l|c|c|}
\hline & Regime 0 & Regime 1 \\
\hline Regime 0 & 0.9 & 0.1 \\
\hline Regime 1 & 0.06 & 0.94 \\
\hline
\end{tabular}

Source: Research Findings.

According to Table (6), the probability that the efficiency of the banking network will remain in regime 0 (high) is $90 \%$, and the probability of remaining in regime 1 (low) is $94 \%$. Therefore, the stability of the flow regime is more efficient than the high regime of the banking network. The possibility of the efficiency of the banking network in future periods should also be specified considering the effect of research variables on the efficiency of the banking network according to its level to be able to make appropriate policy suggestions. Figure (5) illustrates the probability of banking network efficiency in both regimes:

Figure 5. Possibility of Banking Network Efficiency in Different Regimes in Future Periods
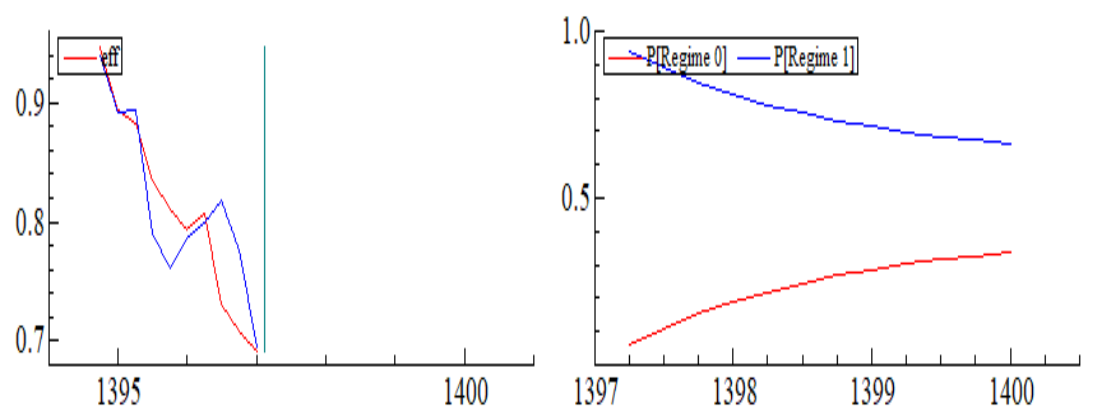

Source: Research Findings.

As can be observed, the probability of being in a low banking efficiency regime is increasing in the future. Table (7) shows the validity and accuracy of the research results. 
Table 7. Goodness of Fit Tests

\begin{tabular}{|c|c|c|}
\hline Test & Statistics & Probability level \\
\hline Jarque-Bera Test & $\mathrm{Chi}^{\wedge} 2(2)=0.82$ & 0.662 \\
\hline Inequality of variance $(\mathrm{ARCH})$ & $\mathrm{F}(1,26)=0.502$ & 0.484 \\
\hline Serial Solidarity (Portamento) & $\mathrm{Chi}^{\wedge} 2(12)=17.38$ & 0.135 \\
\hline
\end{tabular}

Source: Research Findings.

As can be observed, the results of the research model have a high degree of validity because the residues obtained from estimating the model are not correlated according to the goodness-of-fit tests. They also have no variance inequality and have a normal distribution.

\section{Conclusions and Recommendations}

According to the macroeconomic literature, it is impossible to achieve high economic growth without adequate domestic and foreign financing and a highly efficient financial sector. In the present study, at first, the exchange rate fluctuations and stock index variables were extracted using the EGARCH model based on this fact and based on the reality of Iran's economy and the very high share of the banking network in financing. Then, commercial cycles were extracted using the Hodrick Prescott filter. The bootstrap data envelopment analysis approach and Simar and Wilson algorithm were used in GAMS software to extract the efficiency of the banking network. Finally, Markov rotational model was used to estimate the primary research model. The instability of macroeconomic variables such as exchange rates, stock index, and commercial cycles based on the reality of the country and studies can significantly affect the efficiency of the banking network. The results indicated that exchange rate fluctuations have different effects according to the level of efficiency of the banking network.

In a situation where the efficiency of the banking network is low, the exchange rate fluctuations due to the creation of foreign exchange earnings for the government sector and the possibility of payment of loans granted by government institutions and companies increase. Therefore, they can even temporarily settle part of their debt to the banking network. In such cases, the possibility of providing facilities by the banking network increases. However, when the efficiency of the banking network is at a high level with exchange rate fluctuations, the effect of increasing production costs and decreasing product competitiveness and increasing household costs overcomes potential public sector revenues.

Thus, natural, and legal people can deposit and at the same time repay the granted loans. Fluctuations in the stock index due to the small share of this sector in the financing of firms can only slightly increase the efficiency of the banking network if the efficiency is low. If there is an incentive to create fluctuations in the exchange rate, the level of efficiency of the banking network should be considered. High efficiency can reduce the efficiency of the banking network. The capital market must expand by 
creating the right conditions. When the efficiency of the banking network is low, it can bear part of the financing. Expanding the financial deepening through the capital market decreases the probability of reducing the efficiency of the banking network due to the lack of liquidity of companies and the consequent occurrence of bank arrears, which itself affects the ability to grant loans separately for different Islamic contracts. It is possible to prevent further damage to the banking network by expanding and improving the stock index, given that the probability of low-level banking network efficiency in future periods is increasing.

\section{References:}

Amiri, H. 2018. Evaluating the efficiency of selected banks in Iran and its relationship with intra-bank variables and macroeconomic variables. Iranian Journal of Applied Economic Studies, 26, 89-114.

Anvari Rostami, A.A., Kalateh Rahmani, R., Aghaei, M.A., Azar, A. 2018. Evaluating Company Performance Using Financial Ratios: An Application of Bootstrap Data Envelopment Analysis Approach. Sharif Quarterly Journal of Industrial Engineering and Management, 1, 101-109.

Bitar, M., Pukthuanthong, K., Walker, T. 2019. Efficiency in Islamic vs. conventional banking: The role of capital and liquidity. Global Finance Journal, 100487.

Enders, W. 2004. Applied time series econometrics. Hoboken: John Wiley and Sons.

Heidari, H., Zavarian, Z., Nourbakhsh, I. 2011. Study of the effect of macroeconomic indicators on banks' delinquent claims. Quarterly Journal of Economic Research, 11(1), 43-65.

Ismaili, B. 2018. The role of commercial cycles in the overdue receivables of the country's banks using intermediate filters. Quarterly Journal of Financial Economics, 44, 161-188.

Kazerouni, A., Asgharpour, H., Mohammadpour, S., Bahari, S. 2012. Asymmetric Effects of Real Value Fluctuations in Economic Growth in Iran: A Markov Switching Approach. Economic Journal - Bimonthly Review of Economic Issues and Policies, 7, 5-26.

Mensi, W., Hammoudeh, S., Tiwari, A.K., Al-Yahyaee, K.H. 2019. Impact of Islamic banking development and major macroeconomic variables on economic growth: Evidence from panel smooth transition models. Economic Systems.

Partovi, E., Matousek, R. 2019. Bank efficiency and non-performing loans: Evidence from Turkey. Research in International Business and Finance, 48, 287-309.

Philip, H.F. 1988. Time Series Models for Business and Economic Forecasting, Cambridge University Press, New York, 155.

Pourebadollahan Covich, M., Asgharpour, H., Fallahi, F., Sattar Rostami, H. 2018. Study of the effect of micro and macroeconomic variables on the fragility of the Iranian banking system using the Markov switching model. Iranian Journal of Applied Economic Studies, 7(27), 83-111.

Seyed Shokri, K., Grossi, S. 2015. Study of factors affecting the increase of non-performing receivables in the banking system. Semnan. Third National Conference on Accounting and Management, University of Tehran Conference Center.

Shamshur, A., Weill, L. 2019. Does bank efficiency influence the cost of credit? Journal of Banking \& Finance, 105, 62-73. 
Simar, L., Wilson, P.W. 1998. Sensitivity analysis of efficiency scores: How to bootstrap in nonparametric frontier models. Management science, 44(1), 49-61.

Tavakolian, H., Sarem, M. 2017. DSGE models in DYNARE Software (Modeling, Solution and Estimation Based on Iranian Economy). Monetary and Banking Research Institute Publications, First Edition.

Tayeb Nia, A., Ghasemi, F. 2010. Measuring Commercial Cycles in Iran. Quarterly Journal of Economic Research, 45(3).

Verbeek, M. 2005. A Guide to Modern Econometrics. Erasmus University Rotterdam, England, second edition, 300.

Wanke, P., Azad, M.A.K., Barros, C.P. 2016. Financial distress and the Malaysian dual baking system: A dynamic slacks approach. Journal of Banking \& Finance, 66, 118.

Xu, C., Xie, B. 2015. The Impact of Oil Price on Bank Profitability in Canada. 